\title{
Spacing, mirror-image repetition, and memory for pictures
}

\author{
DOUGLAS L. HINTZMAN and LEONARD D. STERN \\ University of Oregon, Eugene, Oregon 97403
}

\begin{abstract}
Two incidental-learning experiments investigated the joint effects of spacing and mirrorimage repetition on memory for pictures. In Experiment 1, the second presentation of a picture $\left(P_{2}\right)$ was always the mirror-image reversal of $P_{1}$. The effect of $P_{1}-P_{2}$ spacing on memory was small and not statistically significant. In Experiment 2, both "reverse $\mathrm{P}_{2}$ " and "identical $\mathrm{P}_{2}$ " conditions were included. A reliable spacing effect was found in both conditions, but the effect was greatly attenuated when $P_{2}$ was the mirror-image reversal of $P_{1}$. This attenuation, resulting from mirror-image reversal, contrasts with the lack of attenuation resulting from switching the input modality of a word from $\mathrm{P}_{1}$ to $\mathrm{P}_{2}$. The result suggests that the left-right arrangement of elements of a picture is a fundamental aspect of the picture's encoding in memory.
\end{abstract}

The effect on memory of the spacing of repetitions is well established: As the interval between presentations of an item increases from 0 to approximately $15 \mathrm{sec}$, long-term retention of the item improves. This general result is obtained using a wide variety of materials and experimental paradigms (Hintzman, 1974, 1976).

An intriguing variation on the spacing experiment is one in which the second presentation $\left(\mathrm{P}_{2}\right)$ is not identical to the first $\left(\mathrm{P}_{1}\right)$, but is related to it in some predetermined way. The results of such experiments are highly variable. If $P_{1}$ and $P_{2}$ are the same word presented in different sensory modalities, the normal spacing effect is found, and its magnitude is apparently unaffected (Hintzman, Block, \& Summers, 1973; Wells \& Kirsner, 1974). If $P_{1}$ and $P_{2}$ are the same concept, presented to bilinguals in two different languages, the spacing effect largely disappears (Glanzer \& Duarte, 1971). If $P_{1}$ and $P_{2}$ are associatively related words, the spacing effect is reversed (Glanzer, 1969; Hintzman, Summers, \& Block, 1975a; Jacoby \& Hendricks, 1973) -that is, short spacings produce better retention than do long spacings. And there is some suggestion that when a verbal and a pictorial representation of the same concept serve as $P_{1}$ and $P_{2}$, the same kind of reverse spacing effect occurs (Paivio, 1974).

This paper reports another manipulation of the relationship between $P_{1}$ and $P_{2}$ that alters the effects of spacing. Stimuli were color photographs (vacation slides), and $P_{2}$ was the mirror-image reversal of $P_{1}$. As a result of mirror-image repetition, the spacing effect was greatly attenuated.

This research was supported by Grant GB-40360 from the National Science Foundation. Requests for reprints should be addressed to Douglas L. Hintzman, Psychology Department, University of Oregon, Eugene, Oregon 97403.

\section{EXPERIMENT 1}

The original purpose of this experiment was to provide additional evidence regarding the locus of the spacing effect. Hintzman et al. (1973) presented $P_{1}$ and $\mathrm{P}_{2}$ of words in different modalities, and inferred from later modality judgments that it is the encoding of $P_{2}$ rather than $P_{1}$ that suffers when $P_{1} \cdot P_{2}$ spacings are short. The intent here was to confirm this conclusion using pictures as experimental materials and using tagging by left-right orientation in place of tagging by modality as a means of differentiating memory of $P_{1}$ from memory of $\mathrm{P}_{\mathbf{2}}$.

\section{Method}

Materials and design. Stimuli were color transparencies of vacation scenes. Pictures with a high degree of right-left symmetry and those in which words or numbers could be read were not used. The continuous study series was presented using two 80 -slide trays. The first 15 and last 5 slides of Tray 1 and the first and last 10 of Tray 2 were filler items. The experimental slides were arranged in six blocks, each including four frequency (F) $=1$ and eight $F=2$ pictures. Two of the latter were repeated at each of four spacings: $0,1,3$, and 7 intervening slides. For all $F=2$ pictures, $P_{2}$ was the mirror-image reversal of $P_{1}$.

The test series consisted of 96 randomly ordered slides: the $24 \mathrm{~F}=1$ and $48 \mathrm{~F}=2$ pictures from the study series, together with $24 \mathrm{~F}=0$ pictures that had not been presented before. Of the $\mathrm{F}=1$ pictures, two from each presentation block were tested in the orientation in which they had been seen originally, and two were reversed. Of the two $F=2$ pictures/block assigned to each level of spacing, one was presented on the test in the $P_{1}$ orientation and one in the $P_{2}$ orientation.

Subjects and procedure. Subjects were 43 paid volunteers, mostly University of Oregon students, tested in groups of from 8 to 13 subjects each. Between groups, pictures were rotated between the $F=0$ and $F=1$ conditions, and $F=2$ pictures were rotated through the four spacings.

Subjects were not told beforehand that a memory test would be given. As an orientation task, they were required to give aesthetic judgments. The study series was presented using a Kodak Carousel projector paced by a timer at a 4-sec rate, and subjects 
indicated their aesthetic feelings about each slide by marking + or - in the corresponding blank on a judgment form. The blanks were numbered 1-160, and the experimenter indicated aloud the number of every 10 th slide.

Following the study series, each subject was given an orientation judgment form. On it were listed the numbers 1-96, with each number followed by the letters $N, S$, and R. Subjects were instructed to respond to each test slide by circling $N$ if the picture was new, $S$ if it had been seen before in the same orientation, $R$ if it had been seen in the reverse orientation, and both $S$ and $R$ if it had been seen in both orientations. The 96 test pictures were then presented at an 8-sec rate.

\section{Results}

Orientation judgments were transformed into frequency judgments by coding response $\mathrm{N}$ as $0, \mathrm{~S}$ or $\mathrm{R}$ as 1 , and both $S$ and $R$ as 2 . The mean frequency judgment for Condition $F=0$ was .08 . Means for the other conditions are shown in Figure 1 . The means for $F=1$ pictures tested in the same and reverse orientations did not differ significantly $[t(42)=.65, p>.05]$. An analysis of variance using planned comparisons was carried out on the judgments made to $F=2$ pictures (overall MSe $=.073$ ). Comparison coefficients used to test for effects of spacing were $-3,-1,+2$, and +2 for spacings of $0,1,3$, and 7 items, respectively. Neither spacing, nor $P_{1}$ vs. $P_{2}$ test orientation, nor the interaction between the two factors was significant $[F(1,42)=2.51,4.01$, and 2.75 , all ps $>.05$ ] .

Subjects' same (S) and reverse (R) judgments made to $F=1$ pictures were fairly accurate. Taking only the pictures subjects said occurred once (an $\mathbf{S}$ or an $\mathbf{R}$ judgment), an average of $77 \%$ of the judgments were correct. There was, however, a strong tendency to circle $\mathrm{S}$. For same-orientation pictures, $\mathrm{S}$ judgments were made $94 \%$ of the time; for reverse-orientation pictures, $\mathbf{R}$

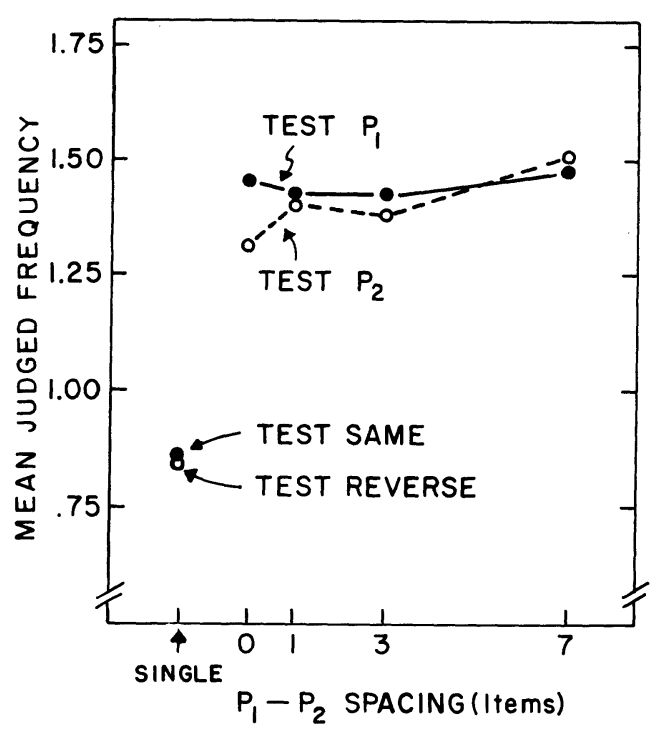

Figure 1. Mean derived frequency judgments from Experiment 1. judgments were made only $60 \%$ of the time. Both the tendency to give $\mathbf{S}$ and its interaction with test orientation were highly significant $[F(1,168)=134$ and 323 , respectively, both ps $<.001$ ]

$S$ and $R$ judgments made to $F=2$ pictures were analyzed in an attempt to determine whether $P_{1}$ or $P_{2}$ suffered more in retention from short $\mathbf{P}_{1} \cdot \mathbf{P}_{2}$ spacings. There were only two statistically significant outcomes: As with $\mathrm{F}=1$ pictures, subjects tended to give $\mathrm{S}$ more often than $\mathrm{R}(69 \%$ vs. $31 \%$ of the time) $[\mathrm{t}(42)=9.29$, $\mathrm{p}<.001]$, and this tendency was stronger when the test orientation matched $\mathrm{P}_{1}$ than when it matched $\mathrm{P}_{2}$ $[t(42)=2.14, p<.05]$. The effect of spacing did not significantly interact with this tendency, which is not surprising given that spacing had no significant effect on judged frequency.

\section{EXPERIMENT 2}

The lack of a significant spacing effect in Experiment 1 is striking when one considers how powerful the effect has been in past studies using pictures (e.g., Hintzman, Summers, \& Block, 1975b). It seems likely that the reversal of pictures on $\mathrm{P}_{2}$ was responsible for this result. However, Experiment 1 differed from previous spacing studies using pictures in another respect: Learning was "incidental" (the orienting task was one of making aesthetic judgments). Possibly, this feature of the experiment, and not the reversal of orientation of $\mathrm{P}_{2}$, attenuated the spacing effect. To assess this possibility, a second experiment was done. The aesthetic judgment task was retained in Experiment 2, and, in addition to the mirror-image repetition conditions, identical repetition conditions were included. On the test, subjects were not asked to give orientation judgments - instead, a standard frequency judgment task was used.

\section{Method}

Stimuli were the same as those used in Experiment 1. They were arranged in four blocks, in two 80-slide trays, with seven fillers at the beginning and five at the end of Tray 1 , and five at the beginning and seven at the end of Tray 2. The four $P_{1}-P_{2}$ spacings were the same as in Experiment 1. Each block included two $F=1$ pictures, eight $F=2$ pictures (two assigned to each spacing) for which $P_{2}$ was the mirror-image reversal of $P_{1}$, and eight $F=2$ pictures (two per spacing) for which $P_{1}$ and $P_{2}$ were identical.

The test series consisted of 80 randomly-ordered slides: eight $F=0$ (new) pictures, $2 \mathrm{~F}=1$ pictures from each block (one tested in the original orientation and one tested in the reverse orientation), eight $F=2$ "reversed $P_{2}$ "pictures/block (one from each level of spacing tested in the $P_{1}$ orientation and one tested in the $P_{2}$ orientation), and eight $F=2$ "identical $\mathrm{P}_{2}$ " pictures per block (one from each level of spacing tested in the original orientation and one tested in the reverse orientation).

A total of 86 paid subjects, obtained as in Experiment 1 , were tested in eight groups of about 11 persons each. Eight assignments of pictures to conditions were obtained by system- 
atically rotating pictures through conditions, between group testings.

Stimulus presentation and the orienting task were the same as in Experiment 1. The test procedure, likewise, was the same, except that a frequency judgment was required. The test form was numbered 1-80, and each number was followed by the digits $0,1,2$, and 3 . Instructions were to circle the digit corresponding to the number of times the picture had occurred in either orientation.

\section{Results}

Mean judged frequency for the $F=0$ pictures was .29. Means for the other conditions are shown in Figure 2. The right panel shows the replication of Experiment 1, and the left panel the effects of identical repetition.

A planned-comparisons analysis of variance (overall MSe $=.131$ ) showed a significant effect of frequency $[F(1,85)=1420, p<.001]$, and an effect of spacing when $P_{2}$ was the mirror image of $P_{1}[F(1,85)=33.3$, $p<.001]$ and when it was identical to $P_{1}[F(1,85)=$ $100.5, \mathrm{p}<.001]$. The interaction of spacing with reverse vs. identical repetition was significant $[F(1,85)=$ $15.31, \mathrm{p}<.001]$, showing that the effect was considerably stronger when the $P_{1}$ and $P_{2}$ orientations were identical. Testing in the original orientation produced higher frequency judgments than did testing in the reverse orientation $[F(1,85)=24.56, p<.001]$. Finally, for the mirror-image repetition items, the interaction of spacing with $\mathrm{P}_{1}$ vs. $\mathrm{P}_{2}$ test orientation was not significant $[F(1,85)=3.14, p>.05]$.

\section{DISCUSSION}

Experiment 1 failed to provide added evidence concerning whether $P_{1}$ or $P_{2}$ is the locus of the spacing effect, primarily because hardly any spacing effect was obtained. Experiment 2 showed that the small magnitude of the spacing effect in Experiment 1 was due to the fact that mirror-image repetitions were used and not to the incidental nature of the learning task.

The spacing effect found with mirror-image repetition was statistically significant only in Experiment 2, but it is clear from

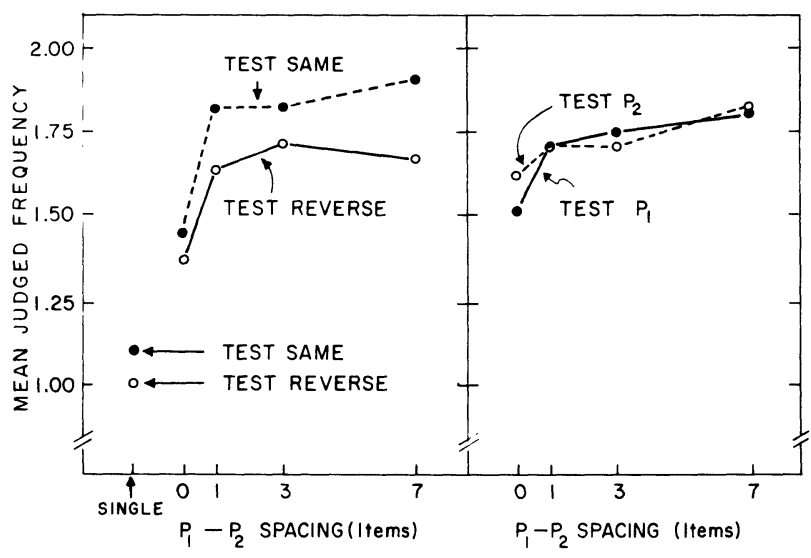

Figure 2. Mean frequency judgments from Experiment 2. Left panel: $P_{2}$ identical to $P_{1}$. Right panel: $P_{2}$ reverse of $P_{1}$. a comparison of Figures 1 and 2 that the results of the two experiments were consistent. The effect is so small that it was only with the greater statistical power of Experiment 2 that it became apparent. Certainly, it is much smaller than the spacing effect obtained when $P_{1}$ and $P_{2}$ are identical.

It is interesting to contrast the effects of mirror-image reversal of pictures, found here, with the effects of manipulating presentation modalities of words, found in other studies. There are two basic comparisons: (1) In the first experiment, orientation judgments, given a correct judged frequency of one, were $77 \%$ correct. This is similar to corresponding figures for auditory-visual modality judgments: $80 \%$ (Bray \& Batchelder, 1972), 74\% (Hintzman, Block, \& Inskeep, 1972), 79\% and $72 \%$ (Hintzman et al., 1973, Experiments 1 and 2). (2) Mirror-image reversal of pictures on $P_{2}$ greatly attenuated the spacing effect. No such attenuation has been found to result from switching the presentation modality of a word (Hintzman et al., 1973; Wells \& Kirsner, 1974).

The results obtained with words suggest that the spacing effect takes place at a "deep," or semantic, level-one which serves as the primary memory code of the word-and that input modality is stored in some auxilary code (perhaps a perceptual trace). Indeed, changes in a homograph's semantic interpretation from $P_{1}$ to $P_{2}$ eliminate the spacing effect (e.g., Madigan, 1969), and translation of words from one language to another (which probably involves a slight semantic change) attenuate it (Glanzer \& Duarte, 1971).

If changing a word's input modality does not alter the spacing effect, why is it nearly eliminated by right-left reversal of a picture? The former manipulation entails a drastic change in the "surface structure" of the stimulus, while the latter manipulation simply reverses one dimension and otherwise leaves all relationships among elements of the scene intact. We offer two answers to this question (both post hoc and possibly indistinguishable): The first is that spatial orientation, as well as semantic interpretation, is an essential component of the "deep structure" representation of a pictorial stimulus. The second is that the perceptual code of a picture plays a far more important role in memory than does the perceptual code of a word.

\section{REFERENCES}

Bray, N. W., \& Batchelder, W. H. Effects of instructions and retention interval on memory of presentation mode. Journal of Verbal Learning and Verbal Behavior. 1972, 11, 367-374.

Glanzer, M. Distance between related words in free recall: Trace of the STS. Journal of Verbal Learning and Verbal Behavior, 1969, 8, 105-111.

Glanzer, M.. \& Duarte, A. Repetition between and within languages in free recall. Journal of Verbal Learning and Verbal Behavior, 1971, 10, 625-630.

Hintzman, D. L. Theoretical implications of the spacing effect. In R. L. Solso (Ed.), Theories in cognitive psychology: The Loyola Symposium. Potomac, Md: Lawrence Erlbaum. 1974.

Hintzman, D. L. Repetition and memory. In. G. H. Bower (Ed.), The psychology of learning and motivation (Vol. 10). New York: Academic Press, 1976.

Hintzman, D. L., Block, R. A., \& Inskeep, N. R. Memory for mode of input. Journal of Verbal Learning and Verbal Behavior. 1972, 11. 741-749.

Hintzman, D. L., Block, R. A., \& Summers, J. J. Modality tags and memory for repetitions: Locus of the spacing effect. Journal of Verbal Learning and Verbal Behavior, 1973, 12, 229-239.

Hintzman, D. L., Summers, J. J., \& Block, R. A. Spacing judgments as an index of study-phase retrieval. Journal of Experimental Psychology: Human Learning and Memory, 1975, 1. 31-40. (a)

Hintzman, D. L., Summers, J. J., \& Block, R. A. What causes the spacing effect? Some effects of repetition, duration, and 
spacing on memory for pictures. Memory \& Cognition, 1975, 3, 287-294. (b)

JACOBY, L. L., \& HENDRICKs, R. L. Recognition effects of study organization and test context. Journal of Experimental Psychology, 1973, 100, 73-82.

MADIGAN, S. A. Intraserial repetition and coding processes in free recall. Journal of Verbal Learning and Verbal Behavior, 1969, 8, 828-835.
Parvio, A. Spacing of repetitions in the incidental and intentional free recall of pictures and words. Journal of Verbal Learning and Verbal Behavior, 1974, 13, 497-511.

Wells, E., \& Kirsner, K. Repetition between and within modalities in free recall. Bulletin of the Psychonomic Society, 1974, 2, 395-397.

(Received for publication June 22, 1977.) 